\title{
Clinical Study of Pregnancy with Congenital Heart Disease in a Tertiary Care Centre
}

\author{
Dr. Jothi Sundaram Md [OG] ${ }^{1}$, Dr. Kavitha Md [OG] ${ }^{2}$, Dr. Karthika Sankar ${ }^{3}$ \\ ${ }^{1}$ Associate Professor, Department of O\&G, Madurai Medical College, Madurai \\ ${ }^{2}$ Assistant Professor, Department of O\&G, Madurai Medical College, Madurai \\ ${ }^{3}$ Postgraduate, Department of O\&G, Madurai Medical College, Madurai
}

\begin{abstract}
Objective: To evaluate the maternal and fetal risks in women with various types of congenital heart disease. Methods: 124 women with various types of heart disease delivered during a period of 5 months from May 2016 to September 2016. This is a prospective study of pregnancy outcome in 80 women with congenital heart disease, among which 58 delivered. The ratio of AHD:CHD was 1.12:1. Results: The various common cardiac lesions were ASD-34, VSD-13, MVP with MR -9, MR - 6, IAS aneurysm - 4,PDA3, TR-2,VSD with PDA -1,bicuspid aortic valve-1, Double chambered RV-1,dilated coronary sinus - 1 and aortic root dilatation $1.47 .5 \%$ were diagnosed in the index pregnancy, $37.5 \%$ had prior surgical correction. $95.6 \%$ belonged to NYHA -I,3.2\% were NYHA II whereas $1.2 \%$ had NYHA-IV at admission. $55.9 \%$ delivered vaginally and $31.25 \%$ had Cesarean section accounting to live birth of 98.3\%. 1 woman had spontaneous expulsion of a dead fetus at 28 weeks. Conclusions: There was no PNMR and no MMR. We have routinely advocated IE prophylaxis in CHD. PPH which causes hypotension should be avoided at all costs.
\end{abstract}

Keywords: Pregnancy, congenital heart disease

\section{Introduction}

The incidence of pregnant women with congenital heart disease (CHD) is increasing as a consequence of progress in the fields of diagnostic techniques and surgical intervention improving their long term outcome. The former ratio of RHD:CHD 3:1 is now reversed .Maternal cardiac and neonatal complications in these women are considerable. The course of pregnancy as well as maternal and fetal morbidity and mortality are dependent on both the underlying defect and the functional maternal state .The 4 predictors of primarycardiac events are prior cardiac event (heart failure, transient ischemic attack, or stroke before pregnancy) or arrhythmia; baseline NYHA class $>$ II or cyanosis; left heart obstruction (mitral valve area $<2 \mathrm{~cm}$, aortic valve area $<1.5 \mathrm{~cm}$ or peak left ventricular outflow tract gradient $>30 \mathrm{~mm} \mathrm{Hg}$ by echocardiography); and reduced systemic ventricular systolic function $\mathrm{EF}<40 \%$.

\section{Methods}

The study was conducted during a period of 5 months from May 2016 - September 2016 on 170 with heart disease. Among which 90 women $(52.9 \%)$ had acquired heart disease and $78(45.8 \%)$ had congenital heart disease whereas 2 $(1.3 \%)$ other women had combined congenital and acquired heart disease.

The ratio of AHD: CHD delivered in our institute was 1.1:1. This is a prospective study of pregnancy outcome in 80 women with congenital heart disease ( 2 being combined). The type of lesion, the timing when the lesion was detected, whether it was surgically corrected or not; functional cardiac status associated medical complications like anemia, chronic hypertension, respiratory tract infections; cardiovascular complications like cardiac failure, arrhythmias, infective endocarditis, thromboembolic complications; obstetric risk factors like PIH, preterm labor, PROM, oligoamnios, APH, mode of delivery, type of anesthesia, maternal outcome and perinatal outcome like LBW, IUGR, preterm baby, congenital malformations and perinatal mortality were evaluated.

Pregnancy was allowed to continue to term and spontaneouslabor was awaited unless laborintervention was dictated for cardiovascular or obstetric indications. One patient had spontaneous expulsion of dead fetus at 28 weeks. All were given infective endocarditis (IE) prophylaxis. All were provided with back rest, nasal oxygen and analgesics during labour . Prophylactic outlet forceps was applied in all cases. LSCS was reserved for patients with obstetric indications and absolute cardiac indications but not followed as routine for cardiac patients. AMTSL was followed in all the cases.

\section{Observations}

ASD was the commonest cardiac lesion diagnosed in our study 34/80 (42.5\%) Among which 31 (38.7\%) had pure ASD, while $2(2.5 \%)$ had ASD with other lesions like MVP and MS (Lutembacher syndrome) and 1 patient had ASD closure with tricuspid valve repair done followed by RHDmoderate MS/MR . The age distribution among the subjects was not very clear with around 53\% belonging to25-30yrs and remaining 20-25yrs. $3(3.75 \%)$ women belonged to more than 30 yrs of age. The percentage of primigravida and multigravida women was equal 50\%. Majority of our patients were in NYHA class-I and II-98.8\% . In our study, 30 women $(37.5 \%)$ had surgical correction of the cardiac lesion prior to pregnancy. 2 patients with VSD/LTGA were on T.lasix 20mg od . 2 patients with ASD were on T.digoxin $0.25 \mathrm{mg}$ od and T.aldactine $25 \mathrm{mg}$ od. 1 patient with ASD and one with VSD were on T.digoxin $0.25 \mathrm{mg}$ od and T.lasix $20 \mathrm{mg}$ od. One woman with VSD closure had severe PHT, she was on T.sildenafil $25 \mathrm{mg}$ bd. 


\section{International Journal of Science and Research (IJSR)}

ISSN (Online): 2319-7064

Index Copernicus Value (2015): 78.96 | Impact Factor (2015): 6.391

\begin{tabular}{|c|c|c|c|}
\hline Type of Lesion & Number & Percentage & Corrected \\
\hline ASD & 31 & 38.75 & 17 \\
\hline VSD & 11 & 13.75 & 6 \\
\hline MVP/MR & 9 & 11.25 & \\
\hline MR & 6 & 7.5 & \\
\hline IAS ANEURSYM & 4 & 5 & \\
\hline PDA & 3 & 3.75 & 2 \\
\hline AS & 3 & 3.75 & \\
\hline TR & 2 & 2.5 & \\
\hline VSD WITH LTGA & 2 & 2.5 & \\
\hline DOUBLE CHAMBERED RV & 1 & 1.25 & \\
\hline BICUSPID AORTIC VALVE & 1 & 1.25 & \\
\hline ASD /MS & 1 & 1.25 & \\
\hline ASD/MVP/MR & 1 & 1.25 & \\
\hline VSD/MR & 1 & 1.25 & \\
\hline PDA/VSD & 1 & 1.25 & 1 \\
\hline DILATED CORONARY SINUS & 1 & 1.25 & \\
\hline AORTIC ROOT DILATATION & 1 & 1.25 & \\
\hline
\end{tabular}

Obstetric Risk factors. Among the patients with anemia $(17.2 \%)$, one patient had severe anemia that was treated with blood transfusion and 2 patients had non severe preeclampsia and were on T.labetalol 100mg bd.

Mode of delivery. In our study of 80 cases of CHD, 58 women delivered. Two woman had second trimester IUD and expelled spontaneously, after gel induction. Out of the 58 women who delivered, 33(56.8\%) had vaginal delivery and Cesarean section was done in $25(43.1 \%)$ mostly for obstetric indications. One patient with double chambered $\mathrm{RV}$ and anomalous muscle bundle in RVOT was taken taken up for emergency LSCS as she went for pulmonary edema and was in ICU care for 5 days. Elective LSCS was done in one patient with VSD closure and severe PHT.Live birth rate in our study was $98.3 \%$, in which LBW babies were $15(25.9 \%)$ and IUGR babies were $3(5.2 \%) .8(13.8 \%)$ were preterm babies. One patient with VSD closure done delivered a baby with left clubfoot and PFO.One patient with VSD closure done taken up for elective LSCS due to CPD II gave birth to baby with multiple cardiac anomalies like IAS aneurysm, muscular VSD,ASD and PDA.12 babies had NICU admission, the indication being preterm, LBW, IUGR ,RDS and MSAF. PNM in our study was 1. One patient with ASD $12 \mathrm{~mm}$ was referred from nearby $\mathrm{GH}$ as atonic PPH following LSCS, which was medically managed by uterotonics oxytocin and carboprost and 2 units of packed cell transfusion. One patient with MVPS delivered vaginally at a local PHC was referred as atonic PPH with DIC and referred to our institution for expert management. She was transfused with blood and blood products and during the hospital stay she developed right lower limb DVT and started on T.acitrom $2 \mathrm{mg}$ HS and was on timely follow up.

\section{Discussion}

ASD was the predominant cardiac lesion detected in our study $(42.5 \%)$. In our study $98.8 \%$ were in NYHA class I \& II. Due to high maternal mortality, termination of pregnancy is indicated preferably in the first trimester in cases with Eisenmenger's syndrome, pulmonary arterial HTN, severe left heart obstructive lesions and Marfan's syndrome with aortic root diameter $>4 \mathrm{cms}$. Termination of pregnancy would be needed in major congenital fetal anomalies. 